\title{
Profound, prelingual nonsyndromic deafness maps to chromosome $10 q 21$ and is caused by a novel missense mutation in the Usher syndrome type IF gene $P C D H 15$
}

\author{
Lance Doucette $^{1}$, Nancy D Merner ${ }^{1}$, Sandra Cooke ${ }^{1}$, Elizabeth Ives ${ }^{1}$, Dante Galutira ${ }^{1}$, \\ Vanessa Walsh ${ }^{2}$, Tom Walsh ${ }^{2}$, Linda MacLaren ${ }^{3}$, Tracey Cater ${ }^{4}$, Bridget Fernandez ${ }^{1}$, \\ Jane S Green ${ }^{1}$, Edward R Wilcox ${ }^{5}$, Larry Shotland ${ }^{5}, \mathrm{XC} \mathrm{Li}^{5}$, Ming Lee ${ }^{2}$, Mary-Claire King ${ }^{2}$ \\ and Terry-Lynn Young*,1
}

\author{
${ }^{1}$ Discipline of Genetics, Faculty of Medicine, Memorial University of Newfoundland, St John's, Newfoundland and \\ Labrador, Canada; ${ }^{2}$ Department of Genome Sciences, University of Washington, Seattle, Washington, USA; \\ ${ }^{3}$ Department of Medical Genetics, Alberta Children's Hospital, Calgary, Alberta, Canada; ${ }^{4}$ Department of \\ Audiology, Janeway Child Health Centre, St John's, Newfoundland, Canada; ${ }^{5}$ Laboratory of Molecular Genetics, \\ NIDCD, NIH, Rockville, Maryland, USA
}

We studied a consanguineous family (Family A) from the island of Newfoundland with an autosomal recessive form of prelingual, profound, nonsyndromic sensorineural hearing loss. A genome-wide scan mapped the deafness trait to 10q21-22 (max LOD score of 4.0; D10S196) and fine mapping revealed a $16 \mathrm{Mb}$ ancestral haplotype in deaf relatives. The $P C D H 15$ gene was mapped within the critical region and was an interesting candidate because truncating mutations cause Usher syndrome type IF (USH1F) and two missense mutations have been previously associated with isolated deafness (DFNB23). Sequencing of the PCDH15 gene revealed 33 sequencing variants. Three of these variants were homozygous exclusively in deaf siblings but only one of them was not seen in ethnically matched controls. This novel c.1583 T>A transversion predicts an amino-acid substitution of a valine with an aspartic acid at codon 528 (V528D). Like the two DFNB23 mutations, the V528D mutation in Family A occurs in a highly conserved extracellular cadherin (EC) domain of PCDH15 and is predicted to be more deleterious than the previously identified DFNB23 missense mutations (R134G and G262D). Physical assessment, vestibular and visual function testing in deaf adults ruled out syndromic deafness because of Usher syndrome. This study validates the DFNB23 designation and supports the hypothesis that missense mutations in conserved motifs of PCDH15 cause nonsyndromic hearing loss. This emerging genotype-phenotype correlation in USH1F is similar to that in several other USH1 genes and cautions against a prognosis of a dual sensory loss in deaf children found to be homozygous for hypomorphic mutations at the USH1F locus.

European Journal of Human Genetics (2009) 17, 554-564; doi:10.1038/ejhg.2008.231; published online 24 December 2008

Keywords: PCDH15; isolated deafness; usher syndrome type IF; hypomorphic alleles

\footnotetext{
${ }^{*}$ Correspondence: Dr T-L Young, Discipline of Genetics, Faculty of Medicine, Memorial University of Newfoundland, St John's, Newfoundland and Labrador, Canada, AIB 3V6.

Tel: + 1709777 6100; Fax: + 1709777 7497; E-mail: tlyoung@mun.ca Received 5 August 2008; revised 24 October 2008; accepted 31 October 2008; published online 24 December 2008
}

\section{Introduction}

An estimated $1 \%$ of all protein-coding genes in the human genome are involved in the perception of sound. Hearing loss is the most frequent form of sensory deficit in the 
world and is often genetic, with more than 400 syndromic types of deafness having been described (www.ncbi.nlm. nih.gov/omim). The majority of human deafness genes have been mapped using extended multiplex families from genetic isolates characterized by phenotypic and genetic homogeneity. The population of the island of Newfoundland is young ( $<20$ generations) with features that make it an excellent resource for mapping disease genes. ${ }^{1}$ The island was colonized by 18000-20000 northern Europeans from southeast England and southwest Ireland who prosecuted the mercantile fishery in the 18-19th centuries off the coast of Newfoundland. ${ }^{2}$ The island population grew almost exclusively from a natural expansion of these English and Irish settlers. Geographic and religious segregation of outport communities have resulted in multiple genetic isolates characterized by high inbreeding coefficients. $^{2-5}$ Several genes underlying medically important disorders have been mapped and identified, ${ }^{6-11}$ including the recent discovery that a novel gene causes an autosomal dominant form of sudden cardiac death because of lethal arrhythmias. $^{12}$

A disproportionate number of deaf children reside on Newfoundland's south coast, a region experiencing persistent isolation because of a lack of roads and limited coastal boat service. We have identified three extended multiplex families with neurosensory hearing loss (Figure 1a), two with autosomal recessive prelingual deafness (Families A and B) and one with a rare form of low frequency loss segregating as an autosomal dominant trait (Family C). We previously used a traditional linkage approach to reveal that a missense mutation in the WFS1 gene causes low frequency hearing loss in Family C. ${ }^{9}$ As of this report, the WFS1 gene reportedly accounts for the vast majority of cases of low frequency hearing loss worldwide, ${ }^{13,14}$ a gene previously associated with a syndromic form of optic atrophy (Wolfram syndrome, OMIM no. 222300). Similarly, functional candidate gene screening in Family B revealed that profound deafness was because of homozygosity or compound heterozygosity for two mutations in TMPRSS3. ${ }^{15}$ We report here that nonsyndromic deafness in Family A maps to $10 \mathrm{q} 21$ and show that deaf relatives are homozygous for an ancestral haplotype and a novel missense mutation in $\mathrm{PCDH} 15$.

\section{Materials and methods}

\section{Family A: Geographical location and clinical} assessment

Family A migrated from England in the early 1800s to settle a fishing outport on Newfoundland's south coast. Persistent isolation is a feature of this coastline because of a lack of roads (Figure 1a). Family A is consanguineous; 7 of the 10 founders are related as either siblings or cousins with five marriage loops confirmed (Figures $1 \mathrm{~b}$ and 5) and overlap in geography with both Families B and C. Informed consent was obtained from 134 relatives (HIC 01.186; Faculty of Medicine, Memorial University and Eastern Health). Pure tone audiometric evaluations showed that 17 relatives had prelingual, severe to profound sensorineural hearing loss (Figures 2 and 3). Complete physical, visual and vestibular exams were carried out on two deaf adults homozygous for the V528D mutation in PCDH15.

\section{Linkage analysis and gene identification}

Genomic DNA from 37 relatives was isolated from blood. ${ }^{16}$ The proband (Figure 5, PID IV-4) was tested for mutations previously identified in the population: GJB2, GJB6, TMPRSS3 and WFS1 (Young, unpublished data). A total of 16 informative relatives were genotyped with 386 polymorphic markers (ABI Prism Linkage Mapping Set-MD10) and alleles scored (ABI 377 analyzer; Genotyper software, version 2.0 Applied Biosystems). Deafness was modeled as an autosomal recessive trait with $100 \%$ penetrance and frequency of 0.001 and analyzed with MLINK (FASTLINK, V4.0P). Genomic DNA was amplified by PCR in $25 \mu \mathrm{l}$ volume and products purified using 50\% sephacryl (Amersham Biosciences) and MultiScreen HTS filter plates (Millipore Corporation). PCR products were sequenced in both directions (BigDye Terminator version 3.1 cycle sequencing kit) to include all exons and flanking intronic sequences of the longest isoform of $\mathrm{PCDH} 15$ $\left(\mathrm{NM}\right.$ _033056) ${ }^{17}$ and CDH23 (NM_022124) ${ }^{18}$ and run on an ABI 3130xl/3700 DNA analyzer (Applied Biosystems). Electropherograms were imported into Mutation Surveyor (version 3.2, Transition Technologies) and haplotypes were constructed manually and ethnically matched populationbased controls were run to determine allele frequencies. ${ }^{19}$ Evolutionary conservation of PCDH15 was determined using ClustalW, Swiss-Prot, TrEMBL, Expasy and displayed with Weblogo. ${ }^{20-22}$ The effects of amino-acid substitutions on protein function ${ }^{22}$ and splicing ${ }^{23}$ were also predicted (specific analyses are available upon request).

\section{Results \\ Genome-wide scan maps deafness to 10q21-22 and reveals an ancestral haplotype}

The proband and several affected members were screened for mutations in GJB2, GJB6, WFS1, and TMPRSS3 and none were found. A $10 \mathrm{cM}$ genome-wide scan mapped the deafness trait to 10q21-22 with a maximum LOD of 4.0 at D10S196 (Figure 4). Genotyping markers flanking D10S196 revealed that deaf individuals in three of the four sibships were homozygous for a $16 \mathrm{Mb}$ ancestral haplotype (Figure 5). Key recombinations in deaf (PID III-16, IV-2, IV-4) and hearing (PID III-14) individuals defined the critical region (D10S1220-D10S1646; Figure 5) that included 44 annotated genes, and overlapped with the Usher syndrome type IF (USH1F; PCDH15 gene) locus. 

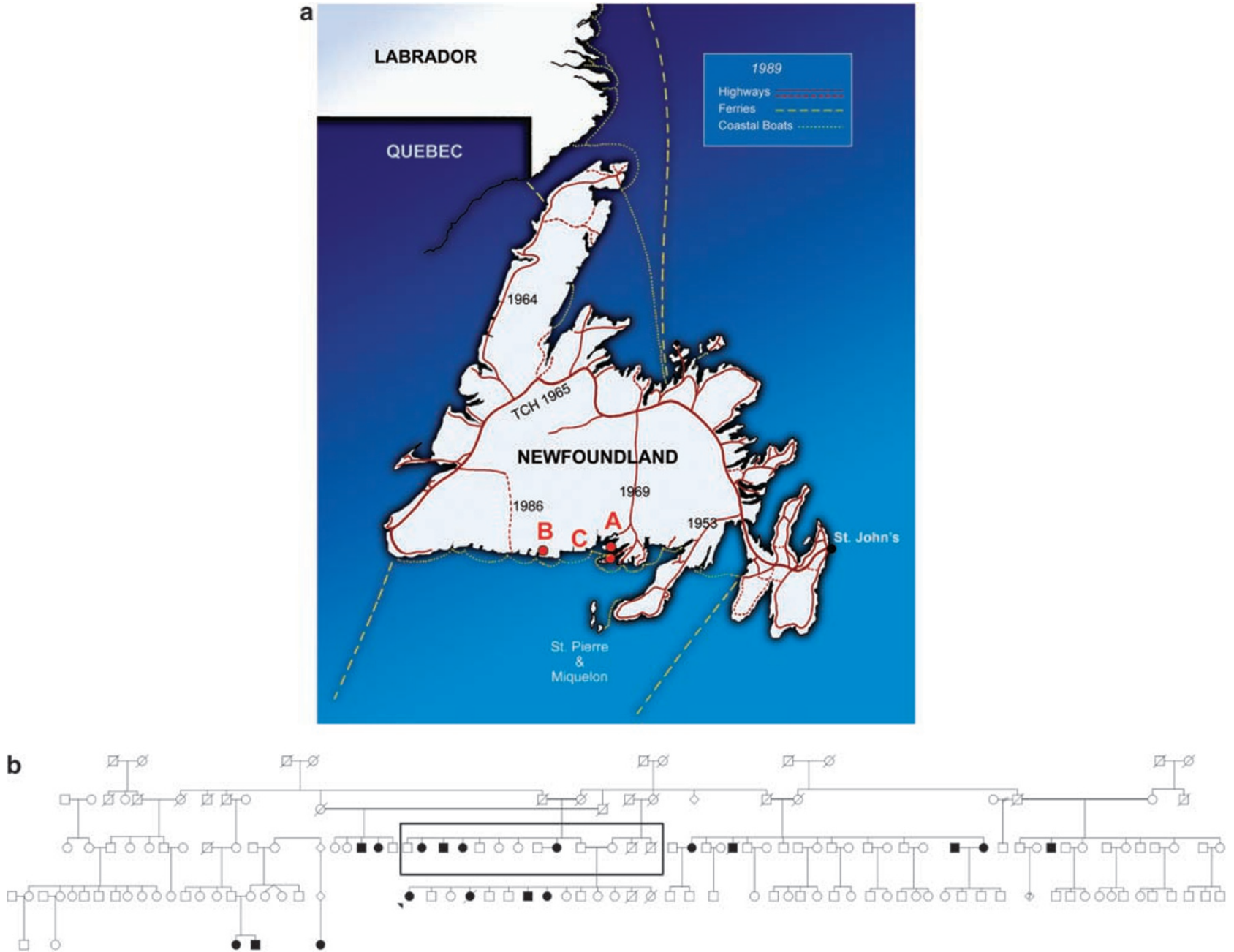

Figure 1 (a) Island of Newfoundland with locations of families A, B, C and the coastal boat route that services this region. Solid land lines = paved highways, broken land lines = unpaved roads, year $=$ completion of road or highway, $\mathrm{TCH}=$ Trans-Canada Highway, Small dotted sea lines $=$ coastal boat service, large dotted sea lines=ferry service to Labrador (top), and Nova Scotia (bottom). (b) Pedigree of family A. Shaded symbols = sensorineural hearing loss. The boxed subpedigree was used for the haplotype analysis.

\section{Sequencing and bioinformatics evaluations of PCDH15 sequencing variants}

Direct sequencing of the 33 exons and intron-exon boundaries of $P C D H 15$ (isoform A; Figure $6 \mathrm{~b}$ ) revealed 33 variants in deaf relatives (Supplementary Table 1). Deaf individuals were homozygous for three of these (c.55 T>G: p.S19A, c.1583 T>A: p.V528D and c.3502-19 C>A). The c.55 $\mathrm{T}>\mathrm{G}$ variant was observed in $37 \%$ of ethnically matched population controls. The c.3502-19 C > A variant is noncoding, is not predicted to alter splicing, and was observed in $6 \%$ of controls (Table 1). In contrast, the c. 1583 $\mathrm{T}>\mathrm{A}$ transversion (Figure $6 \mathrm{a}$ ) predicts a substitution of a valine with aspartic acid (V528D) in the highly conserved fifth ectodomain (EC5) of protocadherin-15 (Figures 6c and 7) and was not observed in the controls (Table 1). In fact, the V528D mutation is predicted to be more deleterious than the R134G and G262D mutations identified in Pakistani families (Figure 7, Table 2), and we conclude that it causes nonsyndromic hearing loss in Family A.

\section{Search for the second pathogenic allele in deaf heterozygotes of $\mathrm{PCDH15}$}

Deaf family members in three of the four affected sibships (Figure 5) were homozygous for both the ancestral haplotype and the V528D missense mutation. However, the deaf offspring of PIDs II-2 and II-3 (PIDs III-1, III-2, III-3, and III-5) inherited a single copy of the ancestral haplotype and the V528D mutation. We reasoned that either these deaf siblings were compound heterozygotes for another mutation in PCDH15, or they were digenic for a second pathogenic allele in another gene. We tested these siblings for mutations found in GJB2, GJB6, WFS1, 


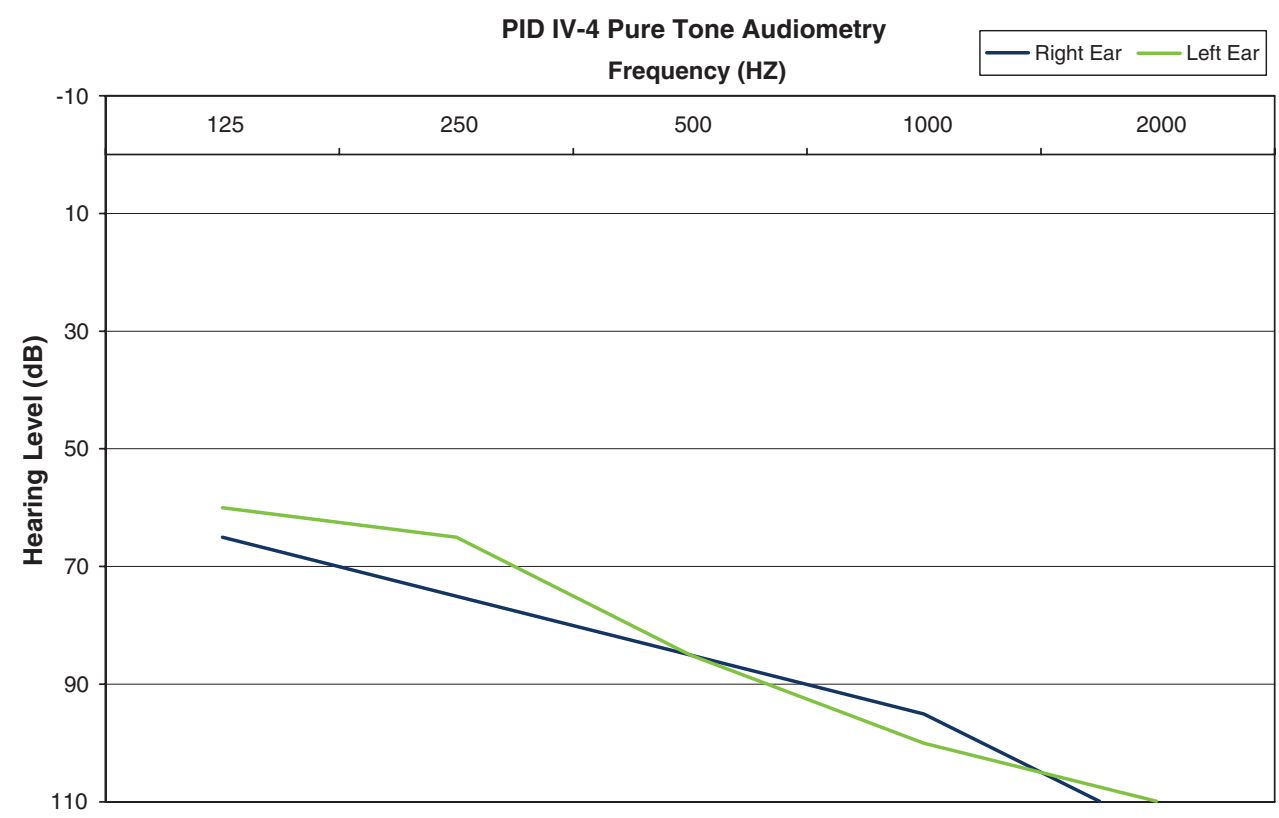

Figure 2 Pure tone audiogram of deaf proband (PID IV-4) (pedigree given in Figure 5). Hearing thresholds (decibels) across all frequencies for both ears are shown.

TMPRSS3 but none were found. Interestingly, cadherin-23, known to interact with protocadherin-15 in the tip links of inner hair cells, is located nearby PCDH15 on 10q21 and digenic interactions have been shown in mice and humans. $^{24}$ To test the possibility that $\mathrm{CDH} 23$ contained a pathogenic allele, we sequenced the long isoform of CDH23 in deaf D528 carriers and identified 44 variants, including 8 coding variants, all classified as nonpathogenic. $^{25}$ To rule out involvement of noncoding elements (5' or $3^{\prime}$ UTR) of $C D H 23$ and $P C D H 15$, we constructed interand intragenic haplotypes across the genomic landscape between $\mathrm{PCDH} 15$ and $\mathrm{CDH} 23$. We did not observe haplotype sharing among these deaf siblings (Supplementary Figure 1). The deaf siblings inherited a different parental contribution. For example, PIDs III-3 and III-5 both inherit a single copy of the ancestral PCDH15 haplotype, but do not share haplotypes on the other homologue. It does not appear that genomic rearrangements and/or deletions are involved as all PCR reactions amplified successfully and alleles segregated in a pattern consistent with Mendelian rules. We conclude that the deaf siblings do not harbor a second pathogenic allele in either $\mathrm{PCDH} 15$ or $\mathrm{CDH} 23$.

\section{Clinical manifestations in deaf relatives}

\section{homozygous for the PCDH15 missense mutation}

Two sisters, individuals PID III-8 and III-12 (Figure 5), underwent extensive clinical testing to rule out features of Usher syndrome type I (USH1). PID III-8 was 46 years, a height of $148 \mathrm{~cm}$ ( < 5 th percentile); weight of $53.8 \mathrm{~kg}$ (25th percentile) and head circumference of $54 \mathrm{~cm}(-0.5 \mathrm{SD})$. No dysmorphic features were observed, ears were normal in position and contour with no tags or pits. Although she was of short stature, this was considered constitutional. Ocular examination revealed no evidence of retinitis pigmentosa (Supplementary Figure 2). Bithermal caloric tests were performed bilaterally and caloric responses were normal and approximately equal bilaterally. Peak velocities, accuracies, and latencies of horizontal saccades were normal. There was no significant spontaneous, positional or gaze evoked nystagmus. The Dix-Hallpike maneuvre provoked no response either with the right or left ear. Horizontal tracking was normal in both directions. We concluded that PID III-8 does not have other clinical signs or symptoms of Usher syndrome. PID III-12, a 50-year-old female, had a height of $153 \mathrm{~cm}$ (5th percentile), weight of $52.4 \mathrm{~kg}$ (25th percentile), and head circumference of $55.5 \mathrm{~cm}(-0.5 \mathrm{SD})$. Ears were normal in position and contour, no ear tags or pits. Apart from some mild upper facial asymmetry, there were no dysmorphic features. Ocular examination revealed no pigmentary retinopathy, and central visual acuity and electroretinogram including scotopic blue and white, and photopic white and flicker stimuli were normal (Figure 3). Caloric responses were normal and approximately equal bilaterally. Peak velocities, accuracies, and latencies of horizontal saccades were normal. There were no reports of tinnitus, aural pressure, balance or dizziness. There was no significant spontaneous, positional, or gaze evoked nystagmus. The Dix-Hallpike maneuvre provoked no response in either the right or left ear. Though based on a small sample set, horizontal tracking was normal in both directions. Horizontal 

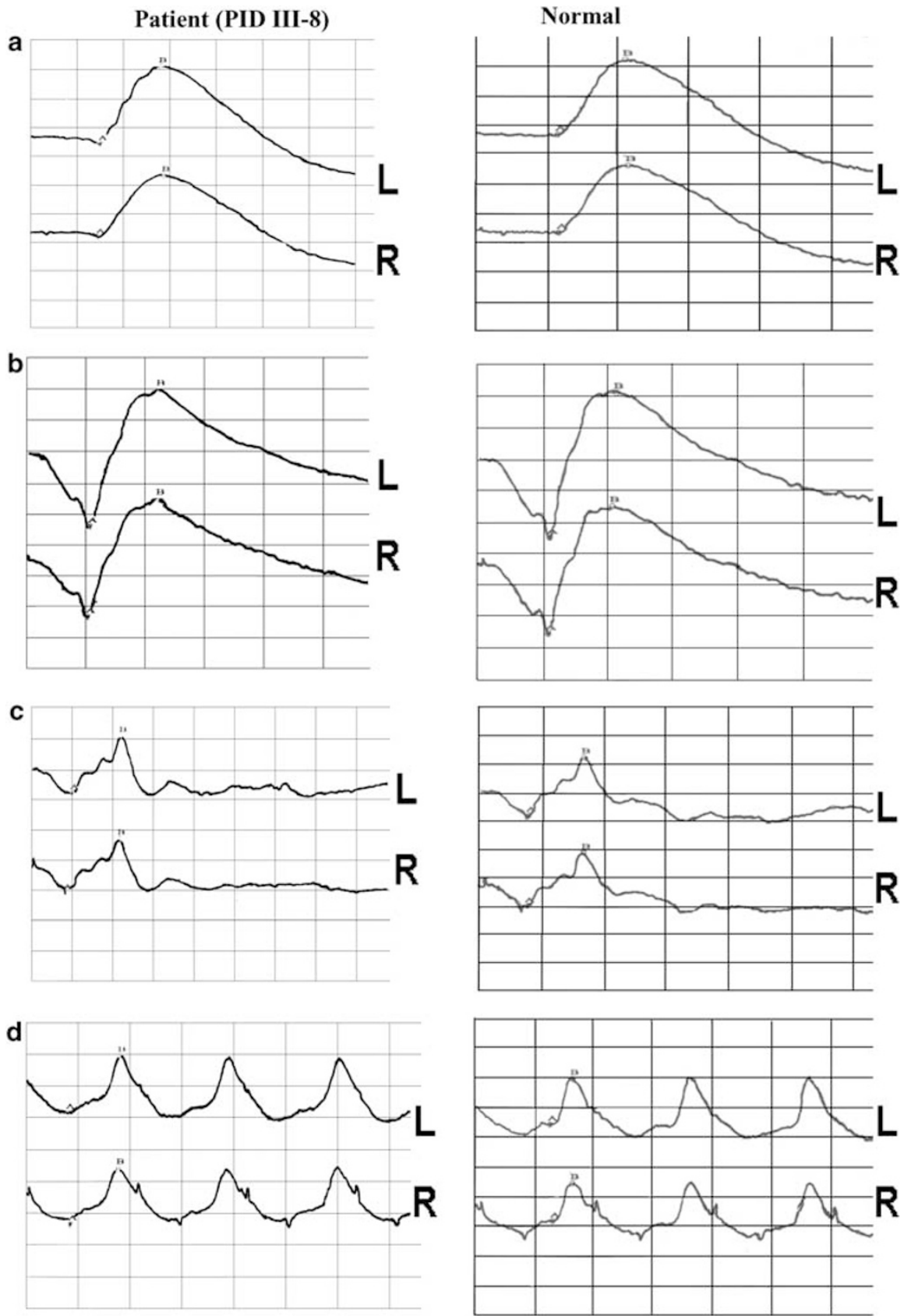

Figure 3 Electroretinograms (ERGs) from individual PID III-8 (pedigree given in Figure 5) located on the left. ERGs on the right are normal ERG values taken from a patient from a separate study. These tests included (a) Seotopic Blue (b) Scotopic White (c) Photopic White (d) Flicker stimuli.

optokinetic nystagmus was normal in both directions. We concluded that PID III-12 does not have any extra-aural features of Usher syndrome.

\section{Discussion}

The sensations of hearing and balance depend on the deflection of bundles of stereocilia on the apical surface of hair cells within the cochlea and vestibulum of the inner ear. Protocadherin-15 is a member of the cadherin superfamily of calcium-dependent adhesion glycoproteins. It is located at the apical pole of these hair cells and interacts with other cadherins via extracellular cadherin domains (ectodomains, EC) to form crosslinks that hold stereocilia together within a hair bundle. The Ames Waltzer (av) mouse exhibits recessive mutations in Pcdh15 and dis- 


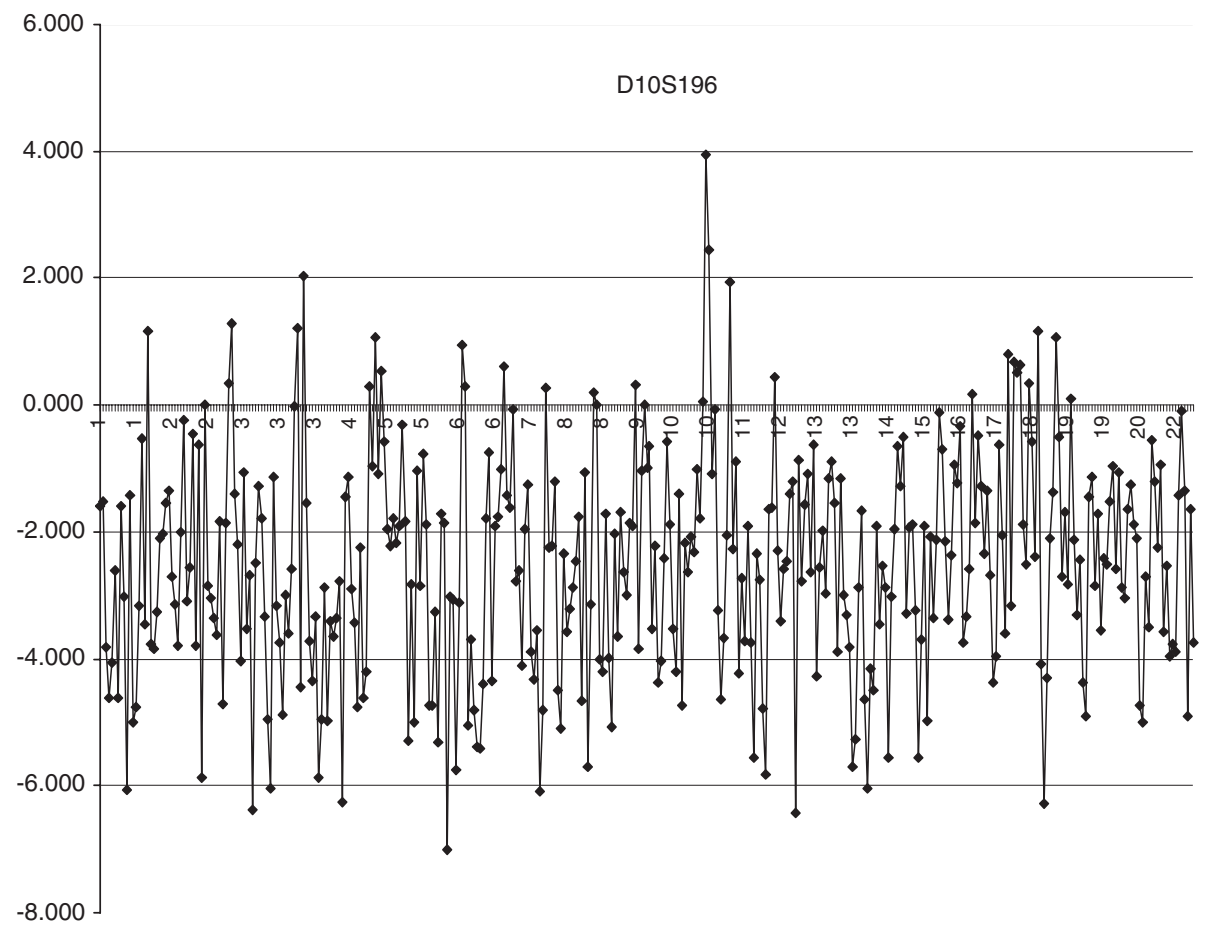

Figure 4 Two-point LOD scores across the genome; against the deaf trait in Family A.

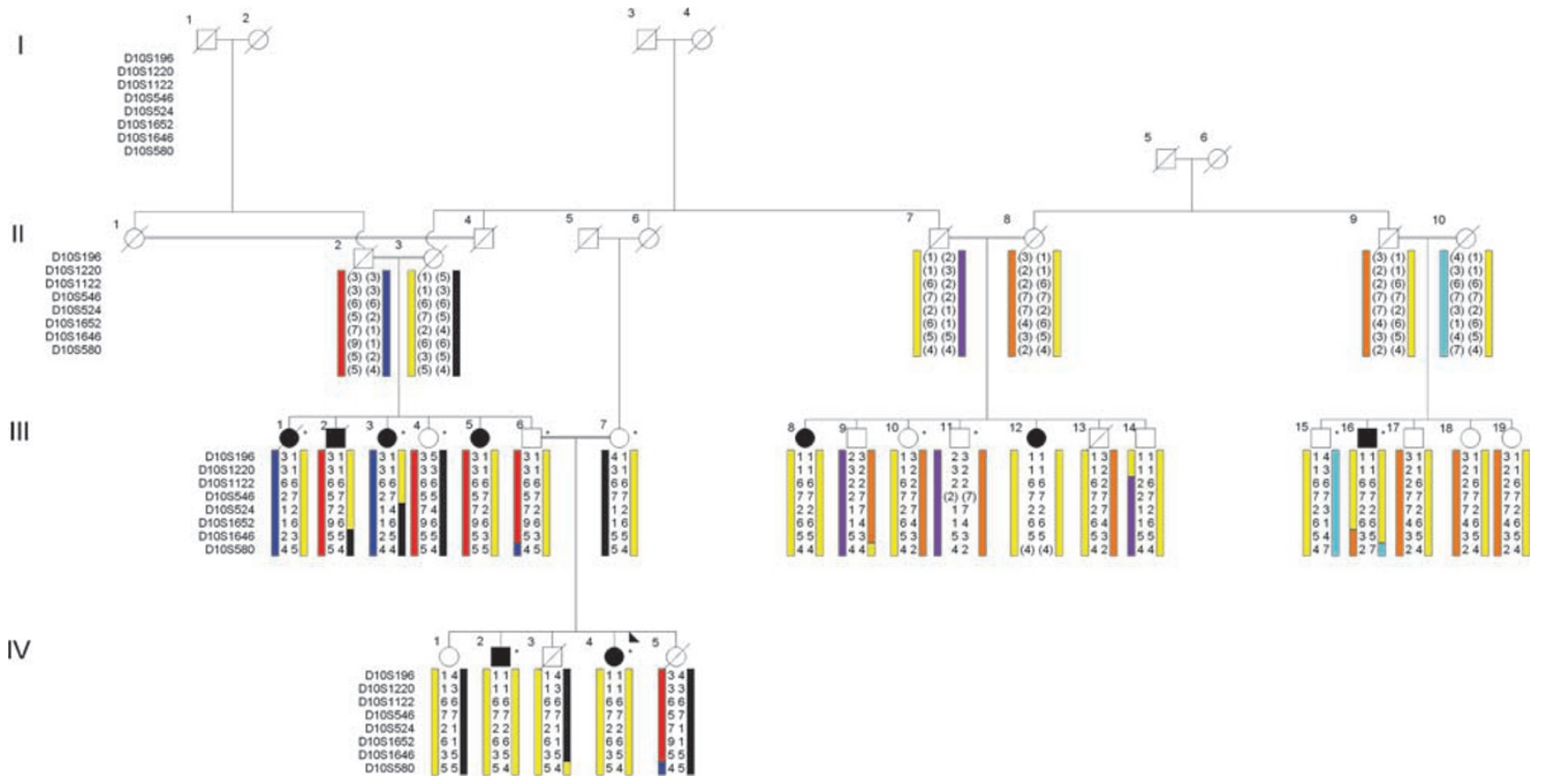

Figure 5 Fine mapping of chromosome l0q2I in family A. Deaf ancestral haplotype is yellow. Individuals with pure-tone audiometry are indicated with an asterisk $\left(^{*}\right)$.

organized bundles of stereocilia and is a model for deafness in USH1F and nonsyndromic deafness (DFNB23). ${ }^{26}$ Recent evidence suggests that cadherin-23 interacts with proto- cadherin-15 to form the specialized tip links that gate the mechanoelectrical transduction channels, converting mechanical energy of sound waves or body movements 

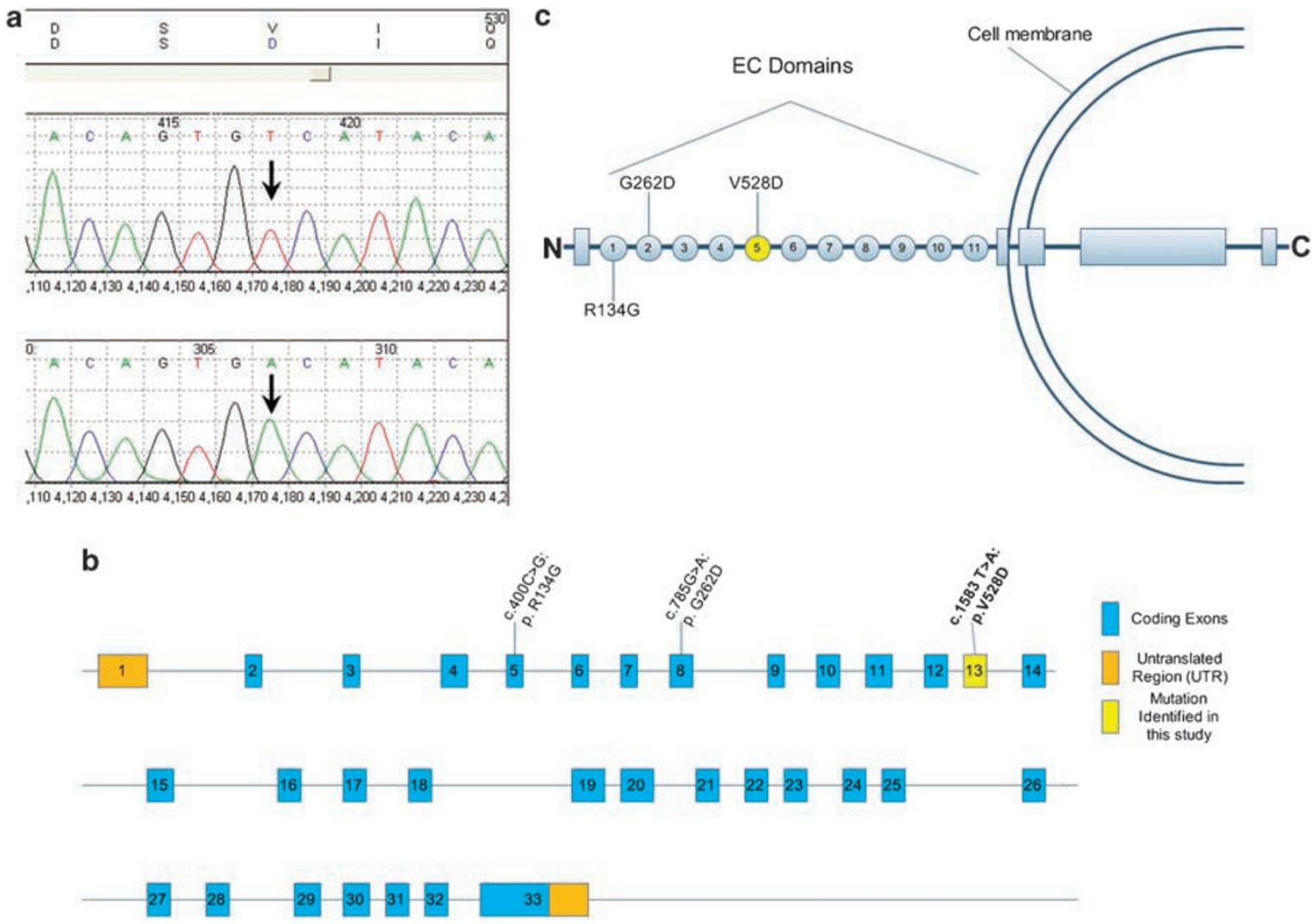

Figure 6 (a) Electropherogram of the c.1583 T>A mutation in a relative homozygous for the V528D point mutation in $P C D H 15$ (reference sequence on bottom). (b) Genomic structure of $P C D H 15$ showing mutations associated with non-syndromic hearing loss (DFNB23) and the novel mutation identified in this study (in yellow/bold). (c) Position of the DFNB23 mutations and the novel V528D mutation in PCDH15.

Table 1 Frequency of $P C D H 15$ sequencing variants that were homozygous in deaf family members in ethnically matched population controls from Newfoundland

\begin{tabular}{|c|c|c|c|c|c|c|c|c|}
\hline \multirow[b]{2}{*}{ Gene name } & \multicolumn{4}{|c|}{ Variant nomenclature } & \multicolumn{4}{|c|}{ Genotype frequency in NL population } \\
\hline & $\begin{array}{l}\text { Accession } \\
\text { number }\end{array}$ & $\begin{array}{l}\text { Coding } \\
\text { nomenclature }\end{array}$ & $\begin{array}{l}\text { Genomic } \\
\text { nomenclature }\end{array}$ & Classification & $\begin{array}{c}W t \\
n(\%)\end{array}$ & $\begin{array}{c}\text { Het } \\
n(\%)\end{array}$ & $\begin{array}{l}\text { Homo } \\
n(\%)\end{array}$ & $\stackrel{\text { Total }}{N}$ \\
\hline PCDH15 & NM_033056 & $\begin{array}{l}\text { c. } 3502-19 \mathrm{C}>\mathrm{A} \\
\text { c. } 1583 \mathrm{~T}>\mathrm{A} \\
\text { c. } 55 \mathrm{~T}>\mathrm{G}\end{array}$ & $\begin{array}{l}\text { g. } 55287049 \mathrm{C}>A \\
\text { g.55613217 } \mathrm{T}>\mathrm{A} \\
\text { g.56093974 } \mathrm{T}>\mathrm{G}\end{array}$ & $\begin{array}{l}\text { Intronic } \\
\text { Missense (V528D) } \\
\text { Missense (S19A) }\end{array}$ & $\begin{array}{l}150(94) \\
152(100) \\
87(56)\end{array}$ & $\begin{array}{c}9(6) \\
0(0) \\
57(37)\end{array}$ & $\begin{array}{r}0(0) \\
0(0) \\
12(8)\end{array}$ & $\begin{array}{l}159 \\
152 \\
156\end{array}$ \\
\hline
\end{tabular}

Abbreviation: Wt, wild type.

into electropotential signals that the brain interprets as sound or acceleration. ${ }^{27,28}$

Both recessive truncating mutations in $\mathrm{PCDH} 15$ and $\mathrm{CDH} 23$ (and several other genes) cause USH1 (OMIM no. 276900), the most severe form of Usher syndrome. This is the second report that recessive missense mutations in PCDH15 can also cause nonsyndromic deafness. The first report in $2003,{ }^{29}$ involved screening $\sim 400$ probands with prelingual hearing loss for markers linked to PCDH15 to test if mutations at the USH1F locus could cause isolated deafness. Three families had recessive mutations in $P C D H 15$, but affected individuals from one of these also had clinical signs of Usher syndrome on follow-up. As a result, two nuclear Pakistani families were reported with two recessive missense mutations in Protocadherin-15. The valine at position 528 that is replaced by an aspartic acid residue in Family A, resides in a highly conserved ectodomain of this USH1 gene and is predicted to be more 

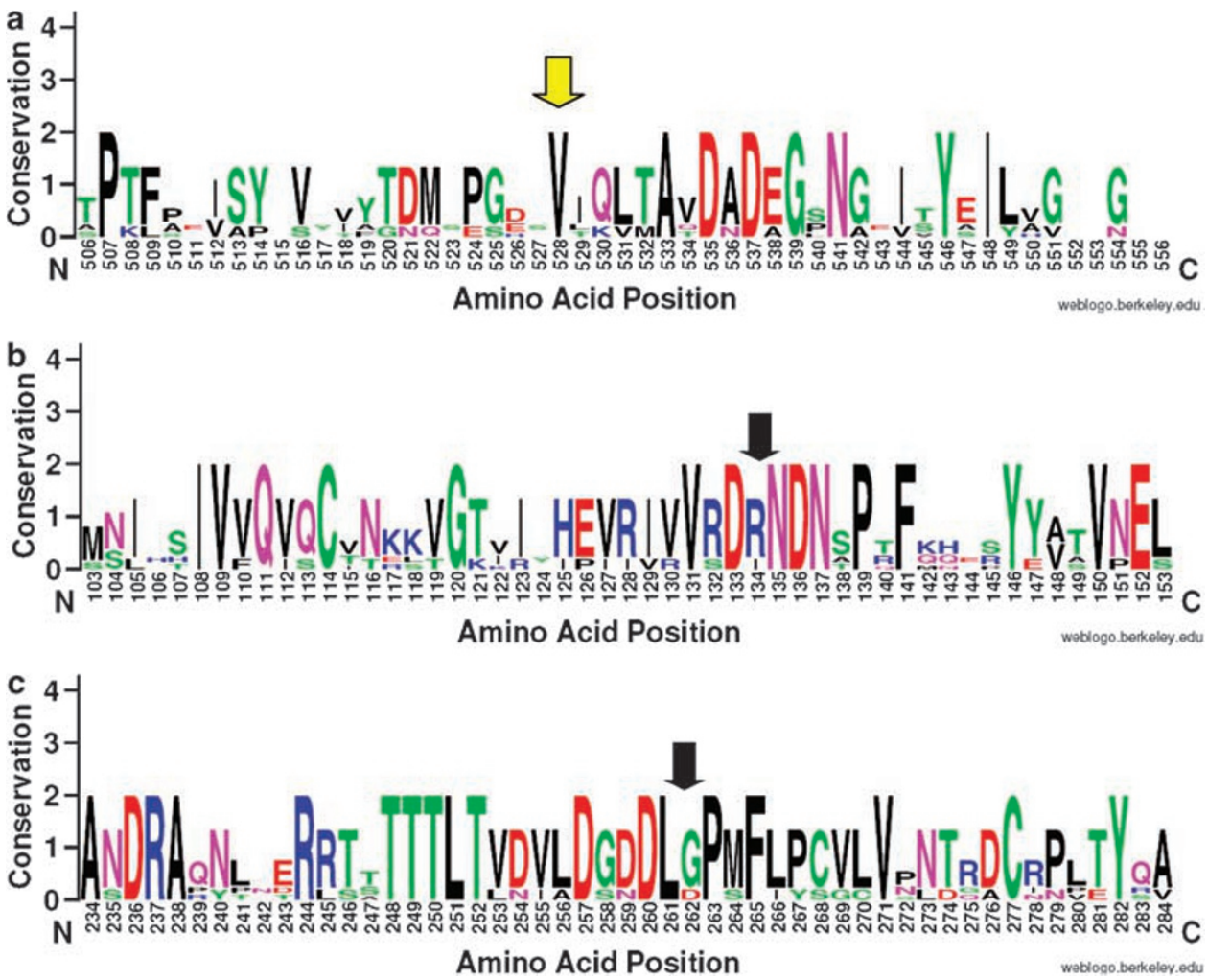

Figure 7 Web logos showing conservation of amino acids in PCDH15 of the (a) V528 residue, the site of mutation in family A (yellow arrow). (b) G262 residue, the site of mutation previously identified in a Pakistani family (c) R134 residue, the site of mutation previously identified in a Pakistani family. Arrows indicate residues of interest.

Table 2 The effects of amino acid substitutions on PCDH15 protein function.

\begin{tabular}{llll}
\hline Variants & SIFT & PANTHER & $\begin{array}{c}\text { Analysis type } \\
\text { PolyPhen }\end{array}$ \\
\hline C.400 C $>$ G, R134G & Tolerated & $P_{\text {deleterious }=0.96403}$ & Probably damaging PSIC score difference: 2.270 \\
c.785 G $>$ A, G262D & Tolerated & No score determined & Possibly damaging PSIC score difference: 1.947 \\
c.1583 T $>$ A, V528D & Not tolerated & $P_{\text {deleterious }=0.99937}$ & Probably damaging PSIC score difference: 2.189 \\
\hline
\end{tabular}

Abbreviation: PSIC, position-specific independent count.

deleterious than R134G in EC1 or G262D in EC2 (Figure 7). ${ }^{30}$ Several minigene constructs have been made of these DFNB23 alleles and the R134G mutation in EC1, but not the G262D in EC2, found to abolish interactions between PCDH15 and CDH23. It was concluded that EC1 of PCDH15 is critical for adhesion and that DFNB23 is caused in part by adhesion defects. ${ }^{31}$ Mutations in EC2 were speculated to cause deafness by affecting the mechanical properties of tip links. ${ }^{28}$ The position of the V528D missense mutation in EC5 (Figure 6c) suggests that it may also cause an adhesion defect. Because clinical features of Usher syndrome because of PCDH15 (USH1F) may not present until later in life, ${ }^{32}$ we conducted a comprehensive visual and vestibular function testing on adults for clinical signs of Usher syndrome but none was found.

Both mouse and human PCDH15 genes have complex genomic structures and transcriptional control mechanisms. ${ }^{27,33,34}$ Human PCDH15 was identified in $2001^{35}$ and was characterized as having 33 exons (isoform A), the first of which is noncoding. This gene encodes a 1955 amino-acid transmembrane protein and 11 ectodomains, one transmembrane domain and a cytoplasmic tail. ${ }^{17,29,35}$ Unlike classical cadherins, the protocadherins have each ectodomain encoded by one or more exons. PCDH15 has its 11 ectodomains encoded by 27 exons of the structural gene. ${ }^{33}$ Multiple alternative PCDH15 transcripts have been 
isolated from the inner ear of mice, some of which have been identified in humans. ${ }^{27}$ These transcripts define four major, alternatively spliced isoforms, which include two new cytoplasmic domains. This raises the number of Pcdh15 exons in mice to 39. Three of these isoforms have different spatiotemporal expression patterns in developing and mature hair cells, suggesting a specific role for each isoform in the sensory hair bundle. ${ }^{27}$ Another isoform of PCDH15 (isoform B) shares only eight exons (26-33) with isoform A and contains two distinct exons (25a and 25b) that encode the transcriptional start site. ${ }^{29}$ The V528D substitution would not be expressed in protein products of isoform $\mathrm{B}$, as exon 13 encoding EC5 resides upstream of the transcription start site of isoform $B$.

There is a single report of a monoallelic mutation in PCDH15 (albeit a $6 \mathrm{bp}$ deletion) in a sibling pair with nonsyndromic sensorineural hearing loss from the UK; however, the significance of this variant was unknown. ${ }^{36}$ To resolve the fourth sibship in Family A (Figure 1) in which deaf relatives were monoallelic for the V528D mutation, we ruled out the possibility that the second pathogenic mutation lies in the interacting cadherin-23 protein by sequence analysis and high-resolution mapping. As no evidence for an interaction was noted, it is more likely that the deaf members in the fourth affected sibship are digenic for the D528 allele and a second pathogenic allele in another gene. Interestingly, Families A and B are both of English extraction, and overlap in geographical location on the south coast of the island. Both also share surnames and have unresolved branches (Figure 1). We searched for this second allele in both unsolved branches of Families A and B by direct sequencing of $\mathrm{CDH} 23$ and TMPRSS3 (data not shown) and haplotype analysis spanning $\mathrm{PCDH} 15$ and $\mathrm{CDH} 23$, but no other pathological variants were found. We suspect that where unresolved branches of Families A and B intersect, a second deaf allele is involved in a digenic interaction with $P C D H 15$, TMPRSS3, or both. Another possibility is that the deafness in these sibships are caused by mutations in a separate gene or by environmental factors.

The emerging genotype-phenotype correlation at the USH1F locus is consistent with findings in these other USH1 genes. Of the seven USH1 loci that have been mapped (USH1B-USH1H), missense mutations in three of these proteins, namely Myosin 7A (MYO7A: USH1B, DFNA11/ DFNB2), ${ }^{37-41}$ Harmonin (USH1C, DFNB18) ${ }^{42}$ and cadherin23 (CDH23, USH1D, DFNB12) ${ }^{43}$ also cause nonsyndromic hearing loss. This study also supports a role for PCDH15 in isolated deafness. Tissue-specific expression of isoforms may determine if mutations in Usher genes cause syndromic or nonsyndromic disease. For example, a mutation at the DFNB18 locus in an exon normally spliced out in the retinal cells may give rise to isolated deafness in the absence of retinal dysfunction. ${ }^{41}$ Perhaps the DFNB23 alleles occur in exons not expressed in the eye. Recently, a novel Usher locus (USH1H) has been mapped to chromosome $15 q 22-23$, which also overlaps the nonsyndromic deafness locus DFNB48, raising the possibility that Usher and nonsyndromic deafness may be caused by nonsense and missense mutation at the same gene. ${ }^{44}$ This would be the fifth of the seventh Type I Usher loci in which missense mutations in strongly conserved motifs cause nonsyndromic deafness.

Exceptions to the genotype-phenotype correlation in Usher syndrome do exist. ${ }^{45}$ Variants identified in cases of Usher syndrome are often presumed to be causative, when they may be rare benign alleles. In a recent report, mRNA studies on four recessive missense mutations classified as Usher mutations (Human Gene Mutation database, HGMD) showed only 1 to alter splicing and result in a truncating mutation. ${ }^{31}$ However, a lack of functional assays for Usher genes makes it impossible to test definitively if mutations affect the expression or function of the protein. Extended, multiplex families can provide supporting evidence by demonstrating co-segregation of a variant with neurosensory impairment. However, in general, caution is required in the interpretation of mutations in USH genes in the absence of family studies or functional studies even if in silico analysis suggests a pathogenic role. ${ }^{46}$ This is critical for correct molecular diagnosis in Usher syndrome to both confirm the diagnosis and inform treatments that are often gene-specific and time sensitive. ${ }^{47}$ For example, early use of cochlear implants may rescue children from a dual neurosensory deficit in cases where the evidence predicts that children will go on to develop retinitis pigmentosa. ${ }^{48,49}$ In this study, DFNB23 alleles predict an isolated deafness, an important distinction from $U S H 1 F$, as there is no evidence from either the Newfoundland or the Pakistani probands that a positive genetic test in children would predict a double sensory loss like that for USH1.

\section{Acknowledgements \\ Thanks to Family A for participation in the study; Herb Martin, Wendy Martin, Andree MacMillan, and Anne Duff for clinical assistance; $\mathrm{Dr}$ Claire-Neville Smith for her early interest in the education of deaf children; and summer student Sonny Collis. This study was supported by CFI New Investigator Award (TLY-project 9384), the Newfoundland Cancer Treatment Research Foundation, Memorial University IRIF award, CIHR operating grant (MOP-66974- $T L Y$ ), the Janeway Children's Hospital Foundation, and the NIH (RO1 DC01076) (M-CK). TLY holds a CIHR/Regional Partnerships Program New Investigator Award (RSH-72586) for research into deafness.}

\section{References}

1 Rahman P, Jones A, Curtis J et al: The Newfoundland population: a unique resource for genetic investigation of complex diseases. Hum Mol Genet 2003; 12: 167R-1172. 
2 Mannion J: The Peopling of Newfoundland: Essays in: Historical Geography. Institute of Social and Economic Research: ISER Books, St John's, Memorial University, 1977.

3 Martin LJ, Crawford MH, Koertvelyessy T, Keeping D, Collins M, Huntsman R: The population structure of ten Newfoundland outports. Hum Biol 2000; 72: 997-1016.

4 Bear JC, Nemec TF, Kennedy JC et al: Persistent genetic isolation in outport Newfoundland. Am J Med Genet 1987; 27: 807-830.

5 Bear JC, Nemec TF, Kennedy JC et al: Inbreeding in outport Newfoundland. Am J Med Genet 1988; 29: 649-660.

6 Young TL, Woods MO, Parfrey PS, Green JS, Hefferton D, Davidson WS: A founder effect in the newfoundland population reduces the Bardet-Biedl syndrome I (BBS1) interval to $1 \mathrm{cM}$. Am J Hum Genet 1999; 65: 1680-1687.

7 Woods MO, Young TL, Parfrey PS, Hefferton D, Green JS, Davidson WS: Genetic heterogeneity of Bardet-Biedl syndrome in a distinct Canadian population: evidence for a fifth locus. Genomics 1999; 55: 2-9.

8 Young TL, Woods MO, Parfrey PS et al: Canadian Bardet-Biedl syndrome family reduces the critical region of BBS3 (3p) and presents with a variable phenotype. Am J Med Genet 1998; 78: $461-467$.

9 Young $\mathrm{T}$, Ives $\mathrm{E}$, Lynch $\mathrm{E}$ et al: Non-syndromic hearing loss DFNA38 is caused by a heterozygous missense mutation in the Wolfram syndrome gene WFS1. Hum Mol Genet 2001; 10: $2509-2514$.

10 Kaurah P, MacMillan A, Boyd N et al: Founder and recurrent CDH1 mutations in families with hereditary diffuse gastric cancer. JAMA 2007; 297: 2360-2372.

11 Ahmad S, Dahllund L, Eriksson AB et al: A stop codon mutation in SCN9A causes lack of pain sensation. Hum Mol Genet 2007; 16: 2114-2121.

12 Merner ND, Hodgkinson KA, Haywood AF et al: Arrhythmogenic right ventricular cardiomyopathy type 5 is a fully penetrant, lethal arrhythmic disorder caused by a missense mutation in the TMEM43 gene. Am I Hum Genet 2008; 82: 809-821.

13 Cryns K, Sivakumaran TA, Van den Ouweland JM et al: Mutational spectrum of the WFS1 gene in Wolfram syndrome, nonsyndromic hearing impairment, diabetes mellitus, and psychiatric disease. Hum Mutat 2003; 22: 275-287.

14 Bespalova IN, Van Camp G, Bom SJ et al: Mutations in the Wolfram syndrome 1 gene (WFS1) are a common cause of low frequency sensorineural hearing loss. Hum Mol Genet 2001; 10: $2501-2508$.

15 Ahmed ZM, Li XC, Powell SD et al: Characterization of a new full length TMPRSS3 isoform and identification of mutant alleles responsible for nonsyndromic recessive deafness in Newfoundland and Pakistan. BMC Med Genet 2004; 5: 24.

16 Miller SA, Dykes DD, Polesky HF: A simple salting out procedure for extracting DNA from human nucleated cells. Nucleic Acids Res 1988; 16: 1215.

17 Ahmed ZM, Riazuddin S, Bernstein SL et al: Mutations of the protocadherin gene PCDH15 cause Usher syndrome type 1F. Am I Hum Genet 2001; 69: 25-34.

18 Bolz H, von Brederlow B, Ramirez A et al: Mutation of $\mathrm{CDH} 23$, encoding a new member of the cadherin gene family, causes Usher syndrome type 1D. Nat Genet 2001; 27: 108-112.

19 Woods MO, Hyde A, Curtis F et al: High frequency of hereditary colorectal cancer in Newfoundland likely involves novel genes. Clin Can Res 2005; 11: 6853-6861.

20 Crooks GE, Hon G, Chandonia JM, Brenner SE: WebLogo: a sequence logo generator. Genome Res 2004; 14: 1188-1190.

21 Combet C, Blanchet C, Geourjon C, Deleage G: NPS@: network protein sequence analysis. Trends Biochem Sci 2000; 25: $147-150$.

22 Gasteiger E, Gattiker A, Hoogland C, Ivanyi I, Appel RD, Bairoch A: ExPASy: the proteomics server for in-depth protein knowledge and analysis. Nucleic Acids Res 2003; 31: 3784-3788.

23 Reese MG, Eeckman FH, Kulp D, Haussler D: Improved splice site detection in Genie. J Comput Biol 1997; 4: 311-323.
24 Zheng QY, Yan D, Ouyang XM et al: Digenic inheritance of deafness caused by mutations in genes encoding cadherin 23 and protocadherin 15 in mice and humans. Hum Mol Genet 2005; 14: $103-111$.

25 Astuto LM, Bork JM, Weston MD et al: CDH23 mutation and phenotype heterogeneity: a profile of 107 diverse families with Usher syndrome and nonsyndromic deafness. Am J Hum Genet 2002; 71: 262-275.

26 Alagramam KN, Murcia CL, Kwon HY, Pawlowski KS, Wright CG, Woychik RP: The mouse Ames Waltzer hearing-loss mutant is caused by mutation of Pcdh15, a novel protocadherin gene. Nat Genet 2001; 27: 99-102.

27 Ahmed ZM, Goodyear R, Riazuddin S et al: The tip-link antigen, a protein associated with the transduction complex of sensory hair cells, is protocadherin-15. J Neurosci 2006; 26: $7022-7034$

28 Kazmierczak P, Sakaguchi H, Tokita J et al: Cadherin 23 and protocadherin 15 interact to form tip-link filaments in sensory hair cells. Nature 2007; 449: 87-91.

29 Ahmed ZM, Riazuddin S, Ahmad J et al: PCDH15 is expressed in the neurosensory epithelium of the eye and ear and mutant alleles are responsible for both USH1F and DFNB23. Hum Mol Genet 2003; 12: 3215-3223.

30 Le Guedard S, Faugere V, Malcolm S, Claustres M, Roux AF: Large genomic rearrangements within the PCDH15 gene are a significant cause of USH1F syndrome. Mol Vis 2007; 13: 102-107.

31 Becirovic E, Ebermann I, Nagy D, Zrenner E, Seeliger MW, Bolz HJ: Usher syndrome type 1 due to missense mutations on both CDH23 alleles: investigation of mRNA splicing. Hum Mutat 2008; 29: 452 .

32 Brownstein Z, Ben-Yosef T, Dagan O et al: The R245X mutation of PCDH15 in Ashkenazi Jewish children diagnosed with nonsyndromic hearing loss foreshadows retinitis pigmentosa. Pediatr Res 2004; 55: 995-1000.

33 Alagramam KN, Miller ND, Adappa ND et al: Promoter, alternative splice forms, and genomic structure of protocadherin 15. Genomics 2007; 90: 482-492.

34 Haywood-Watson II RJ, Ahmed ZM, Kjellstrom S et al: Ames Waltzer deaf mice have reduced electroretinogram amplitudes and complex alternative splicing of Pcdh15 transcripts. Invest Ophthalmol Vis Sci 2006; 47: 3074-3084.

35 Alagramam KN, Yuan H, Kuehn MH et al: Mutations in the novel protocadherin PCDH15 cause Usher syndrome type 1F. Hum Mol Genet 2001; 10: 1709-1718.

36 Hutchin $\mathrm{T}$, Coy NN, Conlon $\mathrm{H}$ et al: Assessment of the genetic causes of recessive childhood non-syndromic deafness in the UK-implications for genetic testing. Clin Genet 2005; 68: 506-512.

37 Astuto LM, Kelley PM, Askew JW et al: Searching for evidence of DFNB2. Am J Med Genet 2002; 109: 291-297.

38 Liu XZ, Walsh J, Mburu P et al: Mutations in the myosin VIIA gene cause non-syndromic recessive deafness. Nat Genet 1997; 16: 188-190.

39 Luijendijk MW, Van Wijk E, Bischoff AM et al: Identification and molecular modelling of a mutation in the motor head domain of myosin VIIA in a family with autosomal dominant hearing impairment (DFNA11). Hum Genet 2004; 115: 149-156.

40 Weil D, Blanchard S, Kaplan J et al: Defective myosin VIIA gene responsible for Usher syndrome type 1B. Nature 1995; 374: $60-61$.

41 Ouyang XM, Xia XJ, Verpy E et al: Mutations in the alternatively spliced exons of USH1C cause non-syndromic recessive deafness. Hum Genet 2002; 111: 26-30.

42 Ahmed ZM, Smith TN, Riazuddin S et al: Nonsyndromic recessive deafness DFNB18 and Usher syndrome type IC are allelic mutations of USHIC. Hum Genet 2002; 110: 527-531.

43 Bork JM, Peters LM, Riazuddin S et al: Usher syndrome 1D and nonsyndromic autosomal recessive deafness DFNB12 are caused by allelic mutations of the novel cadherin-like gene $\mathrm{CDH} 23$. Am J Hum Genet 2001; 68: 26-37. 
44 Ahmed Z, Riazuddin S, Khan S, Friedman P, Riazuddin S, Friedman T: USH1H, a novel locus for type I Usher syndrome, maps to chromosome 15q22-23. Clin Genet 2008.

45 Baux D, Faugere V, Larrieu L et al: UMD-USH bases: a comprehensive set of databases to record and analyse pathogenic mutations and unclassified variants in seven Usher syndrome causing genes. Hum Mutat 2008; 29: E76-E87.

46 Tchernitchko D, Goossens M, Wajcman H: In silico prediction of the deleterious effect of a mutation: proceed with caution in clinical genetics. Clin Chem 2004; 50: 1974-1978.
47 Koenekoop RK, Lopez I, den Hollander AI, Allikmets R, Cremers FP: Genetic testing for retinal dystrophies and dysfunctions: benefits, dilemmas and solutions. Clin Experiment Ophthalmol 2007; 35: 473-485.

48 Loundon N, Marlin S, Busquet D et al: Usher syndrome and cochlear implantation. Otol Neurotol 2003; 24: 216-221.

49 Damen GW, Pennings RJ, Snik AF, Mylanus EA: Quality of life and cochlear implantation in Usher syndrome type I. Laryngoscope 2006; 116: $723-728$.

Supplementary Information accompanies the paper on European Journal of Human Genetics website (http://www.nature.com/ejhg) 